\title{
Da popularização do entorno à evasão da elite: a Rua das Trincheiras, João Pessoa-PB'
}

\author{
Paula Augusta Ismael da Costa*
}

\begin{abstract}
Resumo O cenário atual da Rua das Trincheiras, marcado por ruínas e ocupações irregulares, aponta a existência de conflitos urbanos que se impõem sobre a dinâmica local. Este artigo revela, através da análise de produção deste espaço urbano, que estes conflitos se originaram com a popularização dos entornos das Trincheiras na primeira metade do século XX, instaurando um processo de evasão pelos residentes mais abastados. Diante da retaguarda abandonada, a partir do século XXI as Trincheiras passaram a ser o próprio objeto da apropriação popular, acirrando os conflitos à medida que se torna um espaço de disputa entre diferentes camadas sociais, usos, poderios econômicos e sociais que ora a cobiçam, ora a renegam em séculos de existência, resistência e ocupação.
\end{abstract}

Palavras-chave: produção do espaço urbano, Rua das Trincheiras, Centro Histórico de João Pessoa, expansão urbana.

\section{De la popularización de los alrededores hasta la evasión de la élite: La Rua das Trin- cheiras, João Pessoa-PB}

Resumen El escenario actual de la Rua das Trincheiras, marcado por ruinas y ocupaciones irregulares, apunta la existencia de conflictos urbanos que se imponen en la dinámica local. Este artículo revela, a través del análisis de la producción de este espacio urbano, que estos conflictos se originaron con la popularización de los alrededores de las Trincheras en la primera mitad del siglo XX, estableciendo un proceso de evasión de los residentes más ricos. Frente a la retaguardia abandonada, desde el siglo XXI las Trincheras se convirtieron en objeto de apropiación popular, intensificando los conflictos a medida que se convierte en espacio de disputa entre diferentes estratos sociales, usos, poderes económicos y sociales que a veces lo codician, a veces lo niegan en siglos de existencia, resistencia y ocupación.

Palabras clave: producción de espacio urbano; Rua das Trincheiras; Centro Histórico de João Pessoa; expansión urbana.

\section{From the surroundings' popularization to the elite's evasion: Rua das Trincheiras, João Pessoa-PB}

Abstract Rua das Trincheiras' current scenario, marked by
ruins and irregular occupations, points to the existence of
urban conflicts that are imposed on the local dynamics. This
article reveals, through the analysis of this urban space's pro-
duction, that these conflicts were originated by the popula-
rization of the Trincheiras' surroundings in the first half of
the twentieth century, establishing a process of evasion by
the wealthiest residents. Before the abandoned rearguard,
from the 21 st century the Trincheiras became the very ob-
ject of popular appropriation, intensifying the conflicts as it
becomes a space of dispute between different social strata,
uses, economic and social powers that sometimes covet it,
sometimes deny it in centuries of existence, resistance and
occupation. Keywords: urban space produsction; Rua das Trincheiras; João Pessoa's Historic Centre; urban expansion. 
$-E^{\prime}$

studos iniciados em 2012 acerca de 85 edificações listadas como em "situação de risco" 2 pelo Instituto de Patrimônio Histórico e Artístico do Estado da Paraíba (IPHAEP) culminaram na realização de especialização em 2014. Nas pesquisas de campo empreendidas e nos diagnósticos realizados na ocasião, observou-se que o "abandono" 3 e a degradação destes imóveis inseridos na área de tombamento estadual do Centro Histórico de João Pessoa não acontecia de forma generalizada e homogênea: estes concentravam-se na Área de Preservação Rigorosa ${ }^{4}$ e ao longo de vias importantes - histórica e comercialmente.

Ainda, enquanto alguns locais como a Avenida Walfredo Leal e a Rua da Areia após seis anos de sua listagem recuperaram, respectivamente, $57,15 \%$ e $35,70 \%$ de seus exemplares - bem acima da média global de todos os imóveis elencados (19\%) detectou-se que na Rua das Trincheiras apenas 12,50\% de seu estoque construído fora recuperado. Em contrapartida, houve o o agravamento de $75 \%$ de seus casarios, bem acima da média global (48\%) e dos outros trechos urbanos (Tabela 1).

A partir deste diagnóstico realizado pela pesquisa de especialização foi elaborado um mapa temático que, como observa-se a seguir, espacializa os dados supracitados (Figura 1)

Diante desses resultados, após a conclusão da especialização buscou-se aprofundar as investigações acerca da Rua das Trincheiras no mestrado acadêmico iniciado em 2015, cujo escopo era compreender a instauração e a persistência do processo de "abandono" e degradação na via. Embora a hipótese inicial de que a instauração deste processo foi resultado da descentralização urbana de João Pessoa efetivada na década de 1980 tenha sido refutada na conclusão do trabalho, sua invalidação evidenciou a particularidade da Rua das Trincheiras dentro da dinâmica urbana pessoense.

Destarte, a pesquisa sobre a formação espacial e social da rua no período compreendido entre o final do século XIX até meados do século XX - cujo propósito inicial era prover contextualização histórica para a dissertação - foi essencial para revelar fatores locais que não apenas contribuíram como também condicionaram a instauração e a intensidade do "abandono" local. O principal desses fatores identificados pela dissertação foi a contínua popularização do entorno da Rua das Trincheiras, instaurando conflitos socioespaciais durante o processo de modernização da Cidade da Parahyba (atual João Pessoa) e os acirrando a partir da segunda metade do século XX. Como essa popularização ocorreu e como afeta o recorte espacial até os dias atuais são, portanto,

* Paula Augusta Ismael da Costa é Arquiteta e Urbanista, Mestranda no Programa de Pós-Graduação em Arquitetura e Urbanismo da Universidade Federal da Paraíba, ORCID <http://orcid.org/00000001-7745-9846>. o objetivo principal deste trabalho.

Cabe ressaltar que a identificação deste fator como determinante para o processo de "abandono" e degradação da Rua das Trincheiras foi possível através da análise de produção do espaço urbano a partir da abordagem teórico-metodológica da matriz marxista-lefebvriana. Por meio desta abordagem o estudo das dimensões histórica e 

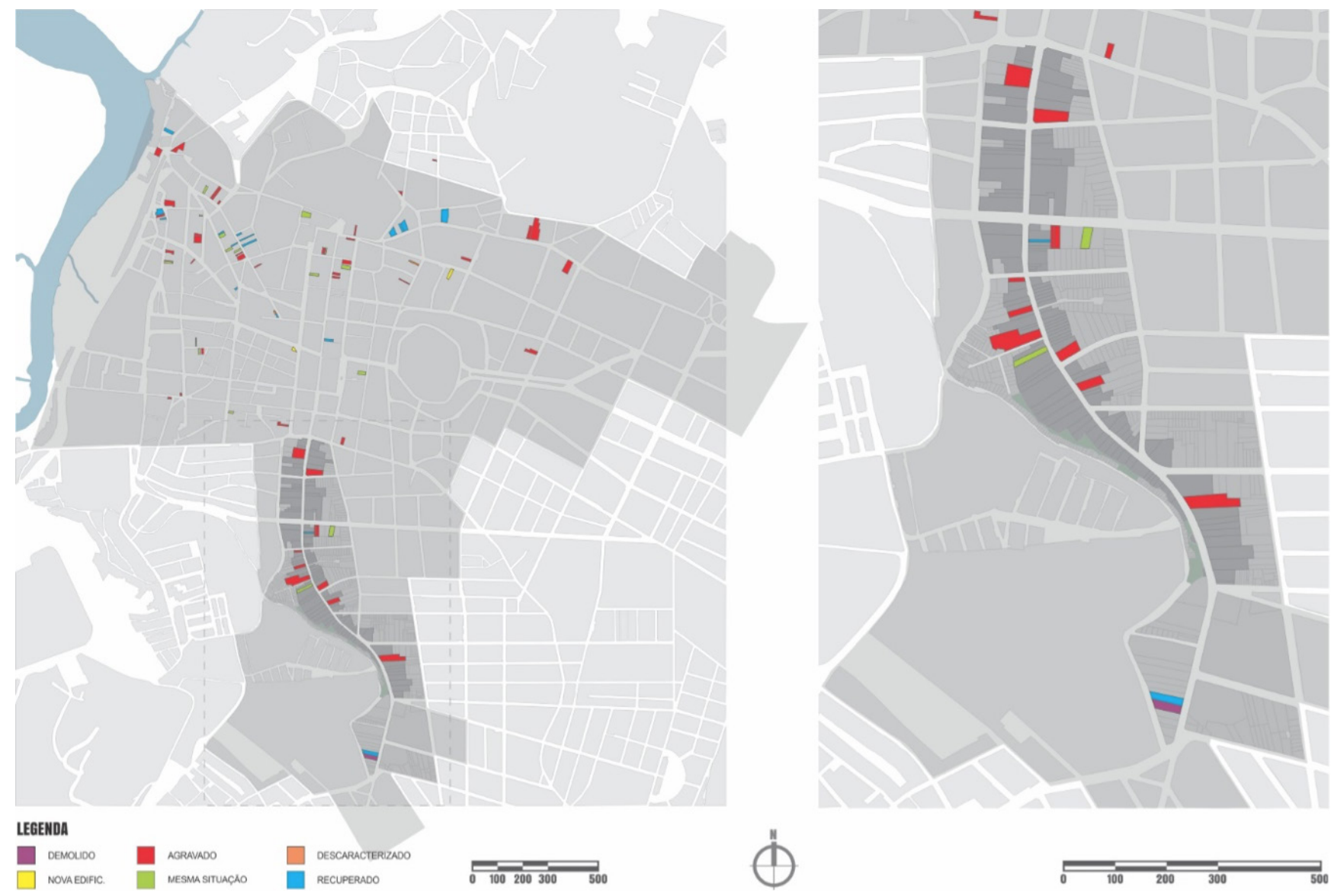

Figura 1: Progresso da situação física dos imóveis no Centro Histórico de João Pessoa (20062012). Fonte - Planta Base da Cidade de João Pessoa/PMJP, editada pela autora, 2017.

\begin{tabular}{|c|c|c|c|c|c|c|c|c|}
\hline SITUAÇÃO & \multicolumn{2}{|c|}{$\begin{array}{c}\text { AV. WALFREDO } \\
\text { LEAL }\end{array}$} & \multicolumn{2}{|c|}{ RUA DA AREIA } & \multicolumn{2}{|c|}{$\begin{array}{c}\text { RUA DAS } \\
\text { TRINCHEIRAS }\end{array}$} & \multicolumn{2}{|c|}{ GLOBAL } \\
\hline AGRAVADA & 03 & $42,85 \%$ & 06 & $42,85 \%$ & 08 & $75 \%$ & 41 & $48 \%$ \\
\hline MESMA SITUAÇÃO & - & - & 02 & $14,30 \%$ & 01 & $12,50 \%$ & 20 & $23,50 \%$ \\
\hline RECUPERADOS & 04 & $57,15 \%$ & 05 & $35,70 \%$ & 01 & $12,50 \%$ & 16 & $19 \%$ \\
\hline DESCARACTERIZADOS & - & - & 01 & $7,15 \%$ & - & - & 05 & $6 \%$ \\
\hline NOVA EDIFICAÇÃO & - & - & - & - & - & - & 02 & $2,50 \%$ \\
\hline DEMOLIDO & - & - & - & - & - & - & 01 & $1 \%$ \\
\hline TOTAL & 07 & $100 \%$ & 14 & $100 \%$ & 10 & $100 \%$ & 85 & $100 \%$ \\
\hline
\end{tabular}

Tabela 1: Progresso da situação física dos imóveis no Centro Histórico de João Pessoa (20062012). Fonte: Elaborado pela autora. 
1 A pesquisa apresentada neste artigo foi realizada com apoio da Coordenação de Aperfeiçoamento de Pessoal de Nível Superior - Brasil (CAPES) - Código de Financiamento 001.

2 Apesar de não definir o que considera como "em risco", analisando os imóveis listados pelo Instituto, pressupõe-se que o critério para seleção dos mesmos foi o estado físico precário. No levantamento constam edificações com má conservação e/ ou arruinamento, assim como edifícios com sinais de degradação fechados ou emparedados, impossibilitando a avaliação completa dos mesmos.

${ }^{3}$ Não se trata de um absoluto abandono da edificação pois não há desistência da propriedade dos imóveis por parte de seus proprietários. Será utilizado o termo "abandono" para aludir à ausência de manutenção da conservação física do imóvel e ao não cumprimento de sua função social.

4 De acordo com o Decreto Estadual $n^{\circ} 25.138 / 2004$, Área de Preservação Rigorosa (APR) "é o conjunto dos logradouros públicos, dos lotes e edificações com qualquer limite voltado para eles [...] cujos elementos que o compõem, inclusive o próprio traçado urbano, devam ser preservados, valorizados, restaurados ou adaptados às características arquitetônicas e urbanísticas originais".

5 "[...] lo histórico, lo diacróni$\mathrm{co}$, el pasado generador, dejan su inscripción incesantemente sobre el espacio, como sobre un cuadro. Los trazos inciertos dejados por los acontecimientos no son lo único que hay sobre y en el espacio; también existe la inscripción de la sociedad en acto, el resultado y el producto de las actividades sociales. [...] El espacio generado por el tiempo es siempre actual, sincrónico y dado como un todo; lazos internos, conexiones que ligan sus elementos, también producidos por el tiempo" (LEFEBVRE, 2013, p. 164). social da rua não foram dissociados da problemática presente do "abandono" local, uma vez que "a produção e o produto se apresentam como dois lados inseparáveis e não como duas representações separáveis" (LEFEBVRE, 2013, p. 96, tradução nossa). Logo, por ser engendrado através de ações acumuladas ao longo dos tempos, entender como este espaço urbano apresenta-se nos dias atuais requereu um estudo que relacionou o espaço físico, o tempo e a sociedade, entendendo-o, desse modo, como um produto social e também histórico. A pesquisa alinha-se, desse modo, ao entendimento de Lefebvre de que,

[...] o histórico, o diacrônico, o passado gerador se inscrevem incessantemente sobre o espacial, como sobre um quadro. Sobre e no espaço, há mais que traços incertos deixados pelos acontecimentos; existe a inscrição da sociedade em ato, o resultado e o produto das atividades sociais. [...] O espaço gerado pelo tempo é sempre atual, sincrônico e dado como um todo; ligações internas, conexões religam seus elementos, elas também produzidas pelo tempo5. (LEFEBVRE, 2013, p. 164 - tradução e grifo nossos)

\section{A formação do locus urbano e a popularização do seu entorno}

A Rua das Trincheiras carrega em seu nome pistas de sua realidade presente: ela não é apenas um elemento morfológico, tampouco uma mera via de circulação de pessoas, de mercadorias ou de veículos. A rua, essa rua, é um espaço de disputa entre diferentes camadas sociais, diferentes usos, diferentes poderios econômicos e sociais que ora a cobiçam, ora a renegam em séculos de existência, resistência e ocupação. Em um primeiro momento foi trincheira que afastou a ocupação dos mais pobres, em um momento posterior foi entrincheirada pela mesma população humilde do qual pretendia distanciar-se.

Seus primórdios são difíceis de precisar: desde o século XVII sua configuração primitiva já figurava nas cartografias holandesas, dois séculos antes de formalizar-se como rua na malha urbana da Cidade da Parahyba. Sua origem pode ser anterior a tais representações cartográficas que, embora não elucidam sua origem, são relevantes por reconhecerem a importante função como rota de circulação de capital e mercadoria da Cidade da Parahyba com a Capitania de Pernambuco que a rua desempenhava.

O início de sua ocupação, por sua vez, é registrado na historiografia local como datado do final do século XVIII, quando, atraída pela construção de um matadouro no local e pelo potencial comércio com viajantes que por ali chegavam, uma população pobre construiu humildes casebres e ali fixaram-se espontaneamente (TINEM, 2006). Não obstante, mesmo com o desenvolvimento de casario esparso na vizinhança, ocupado pela mesma população de baixo poder aquisitivo, e com a instalação de equipamentos importantes como o matadouro público e a da Igreja do Senhor Bom Jesus dos Martírios (atual N. S. de Lourdes) no início do século XIX, para Tinem (2006) a Rua das Trincheiras ainda não se constituía como locus urbano. Para a autora, apenas quando surgem soluções de moradia que "caracterizavam a transição entre o rural e o urbano" que o local passa a assim constituir-se.

A transição supracitada foi iniciada com o processo de urbanização da Cidade da Parahyba engendrado em meados do século XIX, promovido pela elevação do algodão a 
Figura 2: Mapa da Cidade da Parahyba em 1889 com as três linhas de bonde. Fonte - Planta Base da Cidade de João Pessoa/ PMJP, editada pelo autor com base na "Planta da Cidade da Parahyba de 1889" (VIDAL, 2004). principal produto de exportação da Parahyba do Norte e a principal fonte de acumulação de riqueza particular e pública. Entre os anos de 1850 e 1924 uma série de intervenções urbanas realizadas na Cidade da Parahyba foram financiadas pelo tesouro estadual, cujos recursos originários de impostos arrecadados com a exportação e comércio do algodão totalizavam cerca de $50 \%$ da receita, conforme estipulou Guedes (2006).

Para a pesquisadora, se a "falta de dinheiro, estreiteza do mercado interno e o deficiente sistema viário" (GUEDES, 2006, p. 87) foram fatores determinantes para que a urbanização entre o século XVI até meados do século XIX fosse inviabilizada, a prosperidade obtida com a valorização do algodão nos mercados nacional e internacional durante o Período Imperial impulsionou a modernização da cidade e das Trincheiras através de significativas intervenções urbanas e instalações de equipamentos e serviços urbanos modernos. Assim, com base na valorização do produto nos mercados, podese compreender dois momentos distintos nos quais intervenções por ele financiadas pelo algodão repercutiram na formação espacial da Rua das Trincheiras: o primeiro (1850-1914) e o segundo surto do algodão (1915-1924).

No primeiro surto do algodão, as maiores transformações no local foram impulsionadas na década de 1890 a partir da implantação do sistema de bondes à tração animal. 0 equipamento fora proposto pelo governo à Assembleia Provincial uma década antes como medida de dinamização da cidade, uma vez que o poder público responsabilizava a topografia acidentada e a distância entre o núcleo citadino e os sítios de Trincheiras e do Tambiá pelo desinteresse da população em habitar tais locais (MEDEIROS FILHO, 2014). O anseio de incorporar tais sítios ao núcleo citadino é revelado pelas três primeiras linhas inauguradas: a do Comércio, das Trincheiras e de Tambiá (Figura 2).

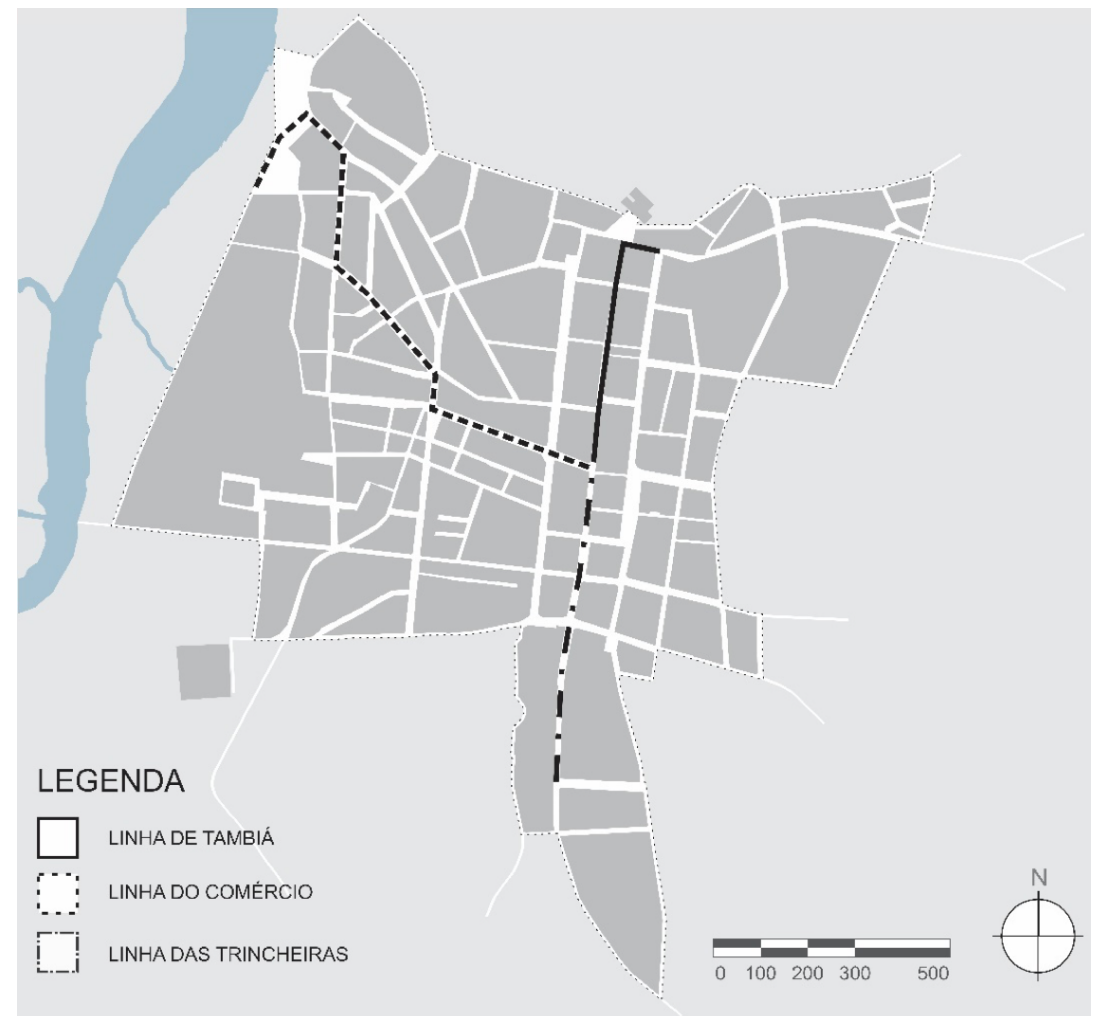


Figura 3: Trecho da Rua das Trincheiras na década de 1920 . Fonte: Revista Era Nova, ano IV, n. 68, set. de 1924.

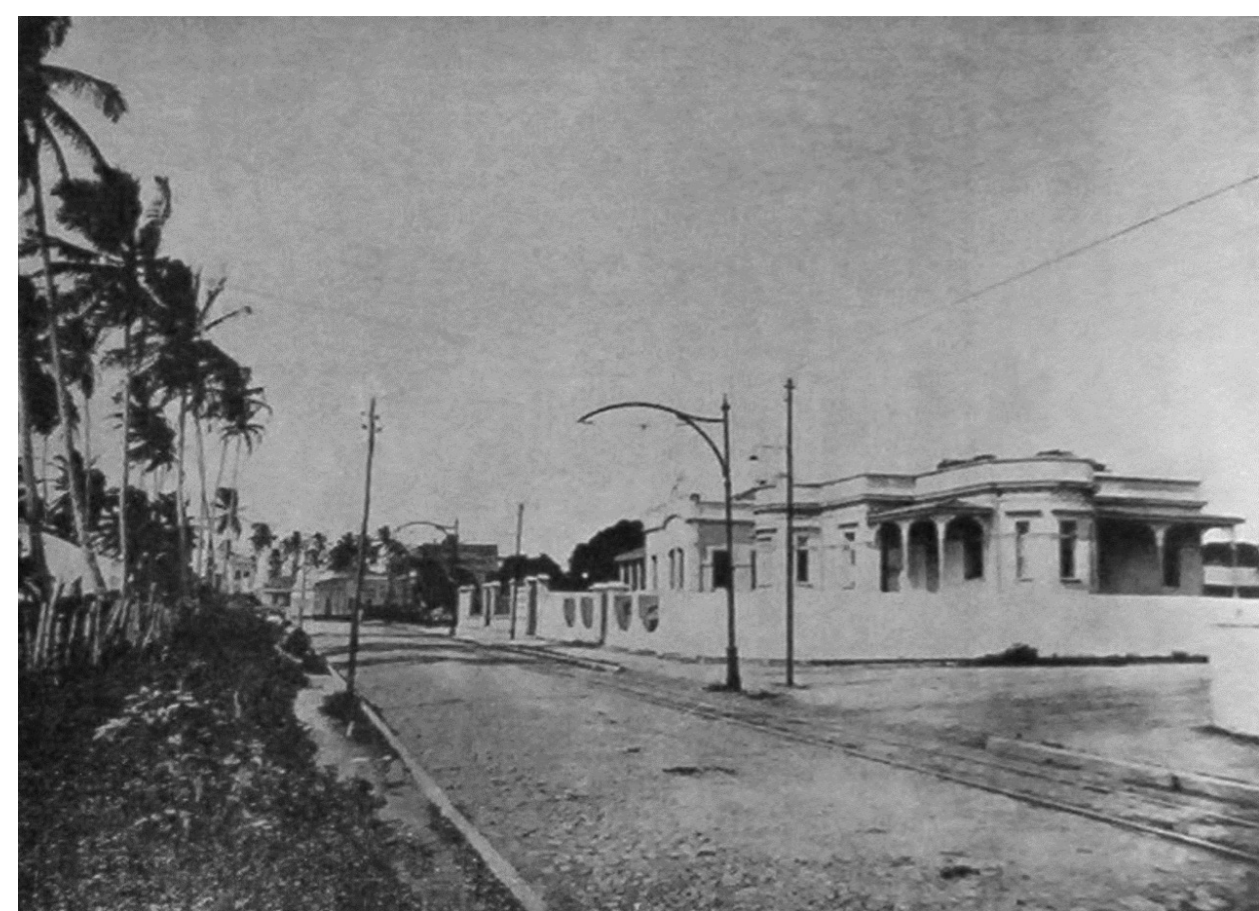

As principais transformações no recorte espacial após a instalação do bonde foram a alteração do padrão e tipologias construtivas e, principalmente, do perfil socioeconômico que ocorriam paulatinamente desde meados do século. Com a apropriação e ocupação do local por membros da camada mais abastada - predominantemente profissionais liberais, ricos comerciantes e proprietários rurais - e a construção de seus casarios, por fim o local elevava-se a locus urbano. No início do século seguinte o bonde continuou sendo um importante meio de incorporação das Trincheiras à Cidade da Parahyba, desenvolvendo-se morfologicamente em quadras e assim transformando-se em bairro.

Após a eclosão da $1^{\text {a }}$ Guerra Mundial, o algodão passou por nova valorização nacional e internacional, e sua exportação gerou o capital necessário para implantar uma política de melhoramentos públicos e a instalação de serviços urbanos importantes como o abastecimento d'água, o saneamento da Lagoa dos Irerês, e a eletricidade. A chegada deste último no ano de 1912 foi um grande marco para a rua e a linha das Trincheiras, pois, além de prover iluminação elétrica para o local, promoveu a substituição do bonde de tração animal por carris elétricos. Os efeitos desta substituição na materialidade da rua não se restringiram à mera colocação ou renovação do calçamento para a instalação dos trilhos do bonde (Figura 3), mas, sobretudo, redundou em constantes prolongamentos da linha do serviço e, consequentemente, no alcance de novas distâncias do Núcleo Primaz.

O estoque construído também se transformava durante os surtos do algodão: a cidade se tornava um verdadeiro "canteiro de obras", onde prédios e espaços públicos, bem 
como edifícios particulares (residências, comércio e serviços) eram construídos ou remodelados, de forma a

[...] atender aos novos costumes de uma sociedade que também se modernizava e ampliava suas exigências por espaços e cenários adaptados ao gosto em voga, trazido por diversos e crescentes meios de comunicação como a imprensa escrita (jornais, revistas, folhetins etc.), o telégrafo, as rodovias, as ferrovias e, inclusive, por viajantes, técnicos e profissionais de outras regiões que vinham à cidade da Parahyba aplicar seus vários conhecimentos na sua remodelação. (GUEDES, 2006, p. 124)

Mesmo em épocas de crise econômica, como a que atingiu o governo de Camillo de Holanda (1915-1920), obras eram empreendidas na rua e no bairro das Trincheiras, demonstrando seu prestígio político e social. Quando se finda o segundo surto do algodão, ainda se observava a construção de suntuosos casarões bem como importantes edifícios públicos no local, com destaque para instituições de saúde e de ensino.

No entanto, ao mesmo tempo em que o poderio econômico e o prestígio político de seus habitantes registravam-se nos investimentos públicos no local, na construção e remodelação de casarios e na ocupação extensiva do local pelas camadas mais abastadas, contraditoriamente esses mesmos ilustres moradores engendravam as razões para sua evasão décadas mais tarde.

Apesar da inicial contradição no argumento anterior - e de sua ironia -, é importante compreender que parte da elite letrada que fixou moradia nas Trincheiras era formada por médicos que gozavam de status social elevado no início do século XX, sendo considerados como "intérpretes das condições dos moradores da Área Central" e mediadores entre o Estado e seus habitantes por Chagas (2004). Em alguns momentos esse status social

6 Os indícios para essa afirmação foram encontrados na tese de Chagas (2004) e na dissertação de Sá (2009), que destacam duas iniciativas que funcionavam na Rua das Trincheiras e que foram importantes para o controle da população pobre: a fundação da Sociedade de Medicina e Cirurgia em 1924 e a atuação do grupo de caridade Noelistas, criado em 1928. A Sociedade, além de ser um local de discussão sobre a situação sanitária da Cidade da Parahyba, a partir de recomendações como a demolição de mocambos, intervinha na permanência dos mais pobres no Núcleo Central. Por sua vez, as noelistas, ao promoverem ações caridosas desprovidas de caráter político, "apenas legitimavam a divisão entre pobres e ricos, e a configuração, na cidade, dos espaços periféricos. Na essência, asseguravam a cidade moderna para alguns, especificamente os que dispunham de recursos econômicos e podiam se apropriar dos serviços implementados" (CHAGAS, 2004, p. 199). converteu-se em poder político, como foi o caso dos médicos e ex-governantes da Cidade da Parahyba João Machado (1908-1912) e Camillo de Holanda (1915-1920).

À medida que as soluções para o saneamento da cidade demonstravam-se ineficazes na erradicação ou diminuição dos riscos de epidemias, e à medida que a visão de que os flagelados da seca e a população pobre em geral eram "agentes transmissores de doenças" propagava-se entre a elite, recomendações eram feitas pelos médicos aos governantes para garantir a salubridade, erradicar epidemias e assegurar a Parahyba como cidade "civilizada" e moderna. Não apenas elementos da "cidade tradicional e escravista" tornaram-se alvos de intervenção, depuração e saneamento, mas a própria vida das camadas pobres passou a ser controlada, o uso do espaço público disciplinado, seus hábitos vigiados e, principalmente, a forma e o local onde moravam passaram a ser regulados (CHAGAS, 2004).

Atuando a partir de recomendações médicas e denúncias feitas pelos membros da elite, muitos destes residentes da Rua das Trincheiras, a Repartição de Higiene decretava a desocupação dos mocambos e adotava uma política de demolições e de queima dos restos das moradas para impedir que seus habitantes os reconstruíssem ou reaproveitassem os materiais (CHAGAS, 2004). Isto é, uma verdadeira guerra foi decretada contra os pobres, seus espaços e seus costumes, munida por legislações e códigos de conduta, e acirrada pelos habitantes de bairros nobres como a Trincheiras, sendo eles peças centrais no debate e nas ações segregatícias ${ }^{6}$. 
Expulsos de suas casas, incapazes de construir moradas adequadas ao Código de Posturas (que exigia a construção em alvenaria e coberta por telhas), e negligenciados pelo poder público devido à ausência de políticas habitacionais, a classe trabalhadora e os flagelados passaram a ocupar áreas periféricas. Todavia, em detrimento de seus esforços de expulsar a população pobre do Núcleo Primaz, ironicamente a elite residente de bairros como Trincheiras atraiu essa população malquista aos seus arredores, destacadamente para os sítios de Cruz das Almas (atual Cruz das Armas) e Jaguaribe.

Quanto ao primeiro, este inicialmente constituiu-se como povoado em 1914, mas elevou-se rapidamente à bairro já em 1923. Devido à grande absorção da classe operária deslocada impositivamente do Centro e à fixação de retirantes da seca no local, - por ali ser porta de entrada dos flagelados que chegavam das cidades interioranas - na década de 1920 Cruz das Almas já contava com 1.265 domicílios e absorvia cerca de $12 \%$ da população da cidade (6.325 habitantes, de um total de 52.990) (NASCIMENTO, 2012). A população pobre também foi atraída a Jaguaribe, cujo crescimento ocorria concomitantemente ao de Cruz das Almas.

Sua ocupação, no entanto, ocorreu de forma disciplinada pela iniciativa privada, e não espontaneamente como no outro arrabalde. A partir do loteamento de sítios de propriedade dos abastados residentes da Rua das Trincheiras e da Avenida João Machado, foi executado o parcelamento do solo de Jaguaribe, não contando, desse modo, com incentivos públicos ou planejamento urbano (ARAÚJO, 2016).

Além de originar um novo padrão de urbanização realizado a partir do loteamento de grandes áreas, também foi inaugurada uma divisão social intrabairro que bem ilustra a dicotomia dos habitantes do novo bairro: enquanto o "Jaguaribe de cima" era reduto da elite e contava com investimentos públicos como a construção do orfanato Dom Ulrico e de um chafariz público, o "Jaguaribe de baixo" era morada dos pobres e negligenciado pelo estado. Para Araújo (2016, p. 261), essa subdivisão foi originada pela própria elite e caracterizava "uma maneira de habitar um bairro de pobres sem admitir a proximidade com aqueles".

Não obstante, assim como em Cruz das Almas, a importância da população de "Jaguaribe de baixo" para o funcionamento da cidade era inegável e, mesmo sem investimentos públicos nos locais e a rejeição pelos vizinhos ricos, suas áreas "desenvolveram-se como um apêndice indispensável da cidade, podendo-se associá-los à senzala ou à área de serviço da cidade" (ARAÚJO, 2016, p. 258). Assim,

Por mais que as medidas implementadas pelos médicos, delegados e prefeitos mantivessem as fronteiras entre o bairro de Jaguaribe e a área central da cidade, um espaço estava imbricado no outro, pois do bairro advinham os trabalhadores domésticos, os do comércio e da indústria relevantes para a manutenção do processo econômico. (CHAGAS, 2004, p. 258)

Devido à concentração operária nesses bairros, surgiu uma importante demanda por transporte público para conduzir os trabalhadores ao centro citadino, e a linha de bonde das Trincheiras tornou-se o fio condutor para novos trechos do sistema. A primeira linha a surgir foi a linha de Cruz das Almas no ano de 1926 a partir do prolongamento da linha de Trincheiras. Entretanto, sua população era servida por veículos de segunda 
Figura 4: Mapa da cidade em $1930 \mathrm{com}$ as linhas de bonde existentes. Fonte: Planta Base da Cidade de João Pessoa/PMJP, editada pelo autor com base na Planta da Cidade em 1930 (VIDAL, 2004). classe que constantemente apresentavam falhas de funcionamento, ocasionando em atrasos das viagens (CHAGAS, 2004).

Na década seguinte, por sua vez, o bonde finalmente foi instalado em Jaguaribe, e seus trilhos conectavam-se aos trechos de Tambiá e Trincheiras (Figura 4). Sua rota também desempenhava a importante ligação com mais uma nova área que se desenvolvia na cidade: o Montepio. Originada como um interstício entre as áreas urbanizadas de Jaguaribe e de Tambiá, era considerada como importante território para a expansão da cidade desde a década de 1910, quando o engenheiro Saturnino de Brito propôs a ordenação do local a partir de avenidas radiais e grandes quadras de geometria irregular. Devido à crise do algodão, no entanto, o plano só foi retomado na década seguinte e o engenheiro, ao retornar à cidade, encontrou o local já parcelado.

A ocupação do bairro só foi intensificada na década de 1930 em decorrência de uma série de fatores como a instalação da linha de Jaguaribe, a construção do primeiro conjunto residencial no local e o saneamento e urbanização da Lagoa dos Irerês (renomeada como Parque Sólon de Lucena). Considerada como um obstáculo geográfico para o crescimento da cidade por séculos, a partir da execução parcial do projeto de extensão da cidade elaborado pelo urbanista Nestor de Figueiredo em 1932, a antiga lagoa finalmente tornou-se o eixo de origem da estrutura viária através de um sistema de avenidas radiais e em centro de irradiação da expansão urbana, cumprindo "[...] um duplo papel de estabelecer uma ligação direta com a cidade existente e, ao mesmo tempo, apontar um caminho sem volta, o crescimento em direção ao mar" (VIDAL, 2016, p. 169).

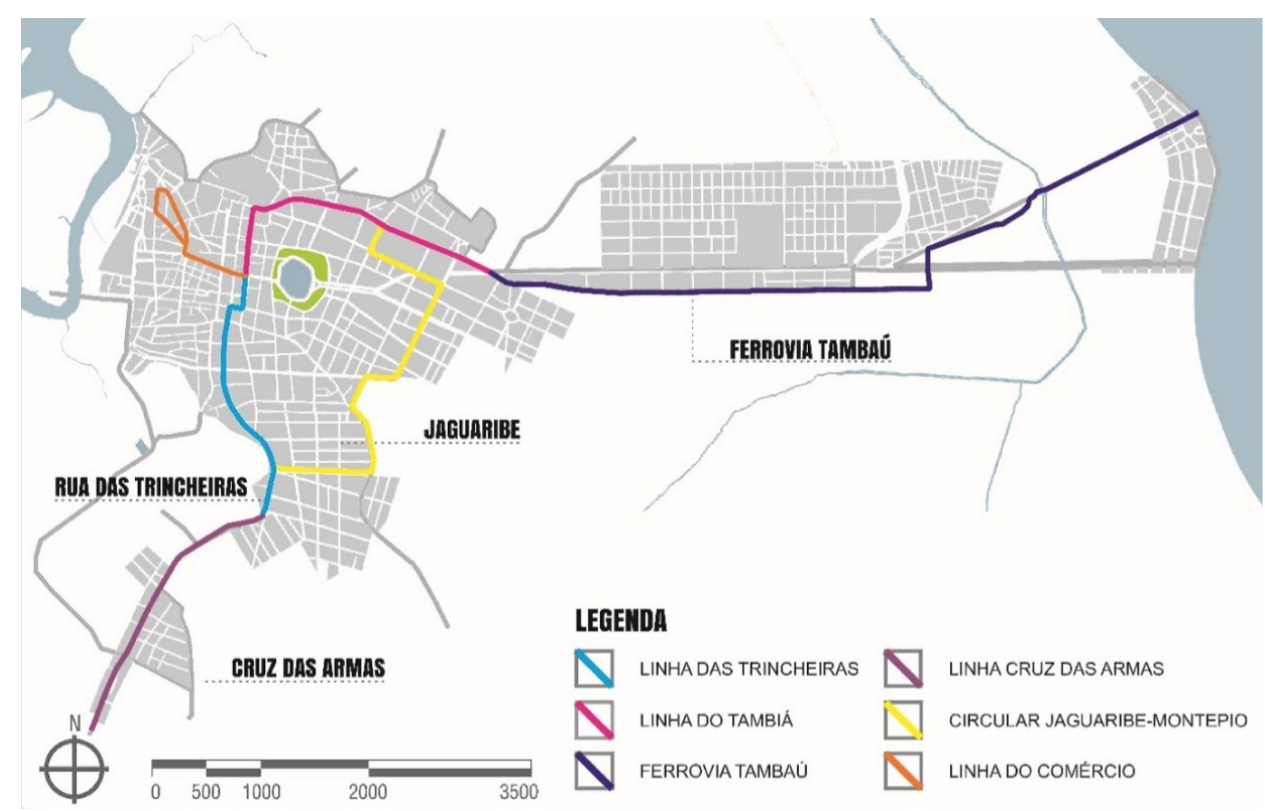


Destarte, o entorno do Parque Sólon de Lucena passou a atrair os residentes ricos da capital paraibana que almejavam afastar-se do congestionamento e adensamento do setor terciário que atingia a Cidade Alta e Tambiá, bem como afastar-se da vizinhança pobre que deles se aproximava vertiginosamente, como no caso de Trincheiras. Não obstante, as condições para consumar a ruptura da Rua das Trincheiras com seus habitantes e com isso engendrar o processo de "abandono" e degradação do local só surgiram décadas depois com a inauguração de um novo padrão de mobilidade e de produção do espaço urbano nas cidades brasileiras.

\section{A evasão da elite e o acirramento dos conflitos urbanos}

A superação dos limites centenários de João Pessoa ocorreu a partir da promoção dos novos territórios nos eixo leste (Centro-Praia) e sul, aliando o crescimento demográfico aos interesses econômicos. Enquanto a expansão em direção à orla era motivada pelos interesses do mercado imobiliário e se apoiava na Avenida Epitácio Pessoa, a ligação com Recife atraía o comércio e o serviço populares para a Avenida Cruz das Armas.

Na primeira metade do século XX a ocupação desses dois setores urbanos era refreada pela rigidez que o transporte sob trilho impunha aos deslocamentos intraurbanos e ao desenvolvimento da malha viária, assim dificultando a criação de novas frentes de acessibilidade na cidade. Tal situação começou a mudar quando um novo padrão de mobilidade territorial foi inaugurado no Brasil como resultado das políticas econômicas adotadas no período da República Nova (1946-1964): a partir da implantação de infraestruturas rodoviárias e energéticas, bem como o estímulo ao consumo de petróleo e de automóveis, aumentou-se a motorização das classes mais altas e novas formas de acesso a novos territórios foram criadas nas cidades brasileiras acessibilidade devido à flexibilidade que os automóveis possuem (SANTOS, 1993).

Para Villaça (1998), esse novo padrão de mobilidade foi justamente a força "simultânea, generalizada e profunda" fundamental para efetivar a ruptura do Centro com a elite que o sustenta pois, à medida que surgiam novas frentes de acessibilidade, a escolha das localizações não era mais condicionada pela proximidade ao Centro, que até então garantia a minimização do tempo e energia de deslocamento. Com isso a nova mobilidade permitiu às classes dominantes, agora motorizadas, considerarem outros fatores na escolha dos locais de moradia, emergindo também um novo padrão de produção do espaço urbano.

Diante dessa conjuntura, em João Pessoa os mercados fundiário e imobiliário aliaram-se à atuação planejada e intensificada do poder público na promoção de novos loteamentos no eixo leste, apelando para ideais e símbolos de status da classe média ${ }^{7}$, conforme revelaram anúncios publicitários em jornais da época. O anúncio do loteamento Jardim Panamérica, por exemplo, revela que não era apenas a terra que estava sendo comercializada, mas fatores vantajosos como amenidades do litoral, valorização financeira, serviços urbanos e, principalmente, a promessa de uma boa vizinhança, sugerindo que em outras áreas consolidadas da cidade havia uma convivência indesejada pelos membros dessa classe.

Esses loteamentos e seus apelos lograram relativo sucesso e iniciaram o processo de ocupação dessas novas áreas ao atrair residentes abastados da Área Central que ali 
8 Utiliza-se o termo a partir da definição de Clemente (2012, p. 36) de que o vazio urbano é "o espaço (lote ou edifício) que não foi concebido como espaço livre público, localizado em área urbanizada, sem ocupação e/ou sem uso, e que, por sua improdutividade, tem uma "conotação negativa" no meio intraurbano, mas que traz consigo o caráter expectante, representando a possibilidade de transformação futura". construíam exemplares da arquitetura moderna residencial e que, com o peso simbólico desses imóveis, reforçavam "a imagem da avenida como o lugar nobre de moradia da cidade, cada vez mais cobiçado pelos mais abastados" (AFONSO e COSTA, 2016, p. 241). Desse modo, empreendimentos como o Jardim Miramar produziram

[...] um encurtamento simbólico e efetivo das distâncias entre esses dois espaços [cidade propriamente dita e a costa marítima], fugindo à lógica regente do processo de expansão urbana e demonstrando a intenção do Estado em funcionar como agente determinante na ocupação de um vasto território que, compondo a cidade desde o início da década de 1930, encontrava-se ainda escassamente habitado, senão totalmente vazio em largos trechos. (TRAJANO FILHO, 2006, n.p - grifo nosso)

Apesar das intenções do Estado e dos investimentos dos mercados fundiários e imobiliários, a promoção dos loteamentos neste eixo ocorria de modo descontínuo e pulverizado e sua ocupação era lenta e rarefeita, deixando grandes vazios rbanos $^{8} \mathrm{em}$ toda extensão da Avenida Epitácio Pessoa. Devido ao caráter estritamente residencial e à falta de infraestrutura urbana em suas adjacências, esses empreendimentos ainda não eram capazes de efetivar a ruptura das classes mais altas com a Área Central, redundando em uma resistência do uso residencial em alguns de seus bairros tradicionais (MARTINS, 2014).

Essa situação começou a mudar no início dos anos 1960 quando, devido ao loteamento das últimas grandes áreas não urbanizadas de Jaguaribe e ao surgimento de novas aglomerações residenciais no entorno de Cruz das Armas, - ambos em decorrência do crescimento demográfico da capital paraibana - a repulsão que os habitantes da Rua das Trincheiras sentiam pelos residentes desses bairros foi exacerbada. Ao mesmo tempo que esses locais se desenvolviam, eclodiam reações contrárias às construções de suas populações, como a "Campanha contra os Mocambos". De iniciativa de membros da elite e apoiada pelo governador Pedro Gondim (1961-1966), a "Campanha contra os Mocambos" tinha como objetivo eliminar os mocambos construídos em Jaguaribe e impedir a construção de novos, de forma a substituí-los por construções em alvenaria (ARAÚJO, 2016). Com esse modus operandi que remontava às práticas da Repartição de Higiene no início do século XX e sua idealização pela mesma classe abastada, tal iniciativa logrou êxito parcial: ao alterar a paisagem do bairro e eliminar seu caráter autêntico e peculiar, Jaguaribe sucumbiu à especulação imobiliária que, colateralmente, resultou em um intenso fluxo de veículos em suas principais vias, à exemplo da Rua das Trincheiras (ARAúJO, 2016).

O trânsito agravou-se quando, buscando dirimir a saturação funcional e o preocupante adensamento que a Área Central pessoense já manifestava, o poder público implementou um plano de estruturação urbana pautado na especialização de áreas e apoiado em um novo anel rodoviário. Enquanto no setor sudeste foi instalado o Campus Universitário, - primeira atividade urbana permanente locada para além dos limites impostos pelo vale do rio Jaguaribe - o Distrito Industrial foi implantado a sul, a partir do prolongamento da Avenida Cruz das Armas. A instalação desse equipamento, bem como as conexões interurbanas que Cruz das Armas possuía, intensificou a extensão das atividades terciárias pelo eixo sul, resultando na absorção do tráfego de veículos pesados como caminhões pela Rua das Trincheiras (LAVIERI e LAVIERI, 1992). 
Como consequência desses processos em Jaguaribe e Cruz das Armas, a rua foi subjugada por uma intensa circulação de veículos e por uma série impactos negativos por ela imposta, como: incompatibilidade da dimensão da rua com o fluxo de automóveis; dificuldade de circulação e insegurança aos transeuntes; degradação ambiental (visual, atmosférica, sonora); e a ausência de locais para estacionamento, uma preocupação emergente. Desse modo, a permanência dos usos mais tradicionais da Rua das Trincheiras - residencial e institucional - era impossibilitada, por fim efetivando a ruptura da elite com o local que, ao evadi-lo, deixava uma retaguarda abandonada que foi sistematicamente (re)apropriada por uma população marginalizada.

A (re)apropriação da Rua das Trincheiras pela população de baixo poder aquisitivo deveu-se, sobretudo, à instauração da nova política habitacional do Regime Militar que, assim como outras políticas urbanas, era parte da estratégia do governo federal para reaquecer a economia nacional e "desenvolver" o país. Com a criação do Banco Nacional de Habitação (BNH) e do Sistema Financeiro de Habitação (SFH), a partir de 1964 grandes obras de infraestrutura, equipamentos urbanos e habitação foram implantados em João Pessoa e outras cidades brasileiras, sendo a construção de conjuntos habitacionais e o financiamento individual de moradia pelo Sistema Brasileiro de Poupança e Empréstimo (SBPE/SFH) seus principais meios de atuação (CAVALCANTI, 1999).

Através da pesquisa de Lavieri e Lavieri (1992), observou-se uma notável discrepância na distribuição dos financiamentos e empreendimentos do BNH e SFH na cidade pois tal distribuição seguia a lógica e demanda dos mercados imobiliário e fundiário: enquanto o eixo Centro-Praia beneficiou-se com 75,5\% dos domicílios construídos em loteamentos e por cerca de 70\% dos financiamentos do SBPE entre 1964 a 1974, neste mesmo período a soma dos investimentos no Centro, Jaguaribe, Tambiá e Roger foi de apenas $8,2 \%$. Ainda, por mais que o setor sul tivesse sua ocupação por eles estimulada, - à exemplo da construção de conjuntos como o "Cidade dos Funcionários I" (no extremo sul da Av. Cruz das Armas) e o "Costa e Silva" (próximo ao Distrito Industrial) - havia um claro desinteresse do setor privado na promoção de tais empreendimentos, uma vez que os consideravam de baixa rentabilidade devido ao público-alvo. Logo, enquanto os conjuntos construídos na região sul reforçavam a configuração socioeconômica local, os financiamentos do SBPE eram poucos e pulverizados, uma vez que estes eram reservados para áreas nobres e mortuários ricos (LAVIERI e LAVIERI, 1992).

A volatilidade dos financiamentos durante a década de 1970 também evidencia a principal preocupação do BNH e do SFH: o retorno financeiro. Diante da inadimplência dos mutuários de baixo poder aquisitivo e do crescimento da economia nacional, no início da década o banco reorientou os investimentos para a priorização dos financiamentos do SBPE. Com aumento de $288 \%$ comparado à década anterior, em João Pessoa isso resultou em uma maior valorização do solo no eixo da Avenida Epitácio Pessoa e na orla, destino de $51 \%$ e $18 \%$ respectivamente. Na segunda metade dos anos 1970 , todavia, a desaceleração econômica nacional levou à diminuição do financiamento SBPE e à priorização dos conjuntos habitacionais como forma de estimular a indústria da construção civil, absorver um grande volume de mão-de-obra desqualificada e dinamizar outras indústrias e o setor imobiliário. Mesmo com a oscilação dos tipos de investimentos e do público-alvo, as implicações das políticas habitacionais do 


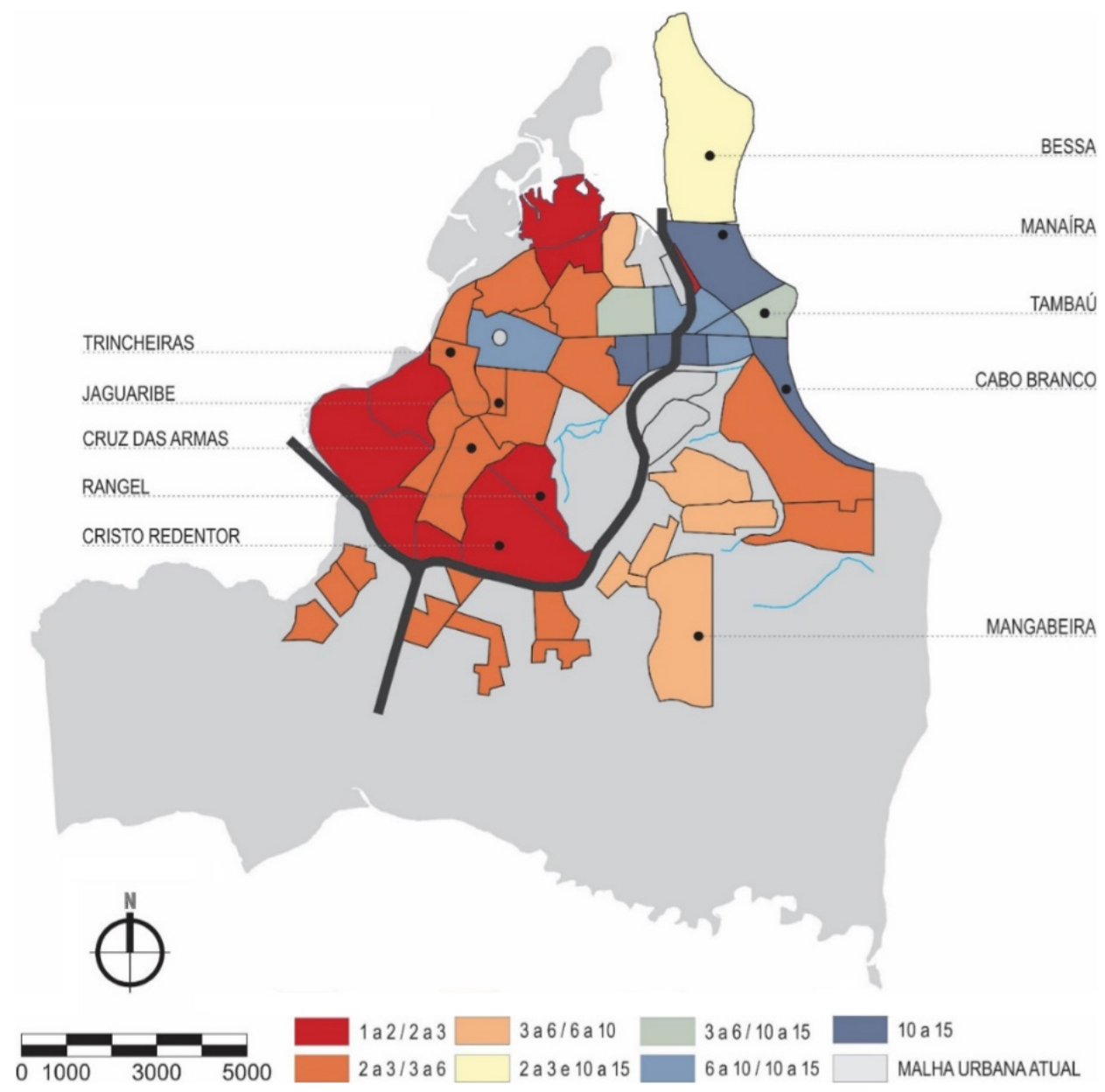

Figura 5: Renda média familiar predominante em salários mínimos (1983). Fonte: Planta Base da Cidade de João Pessoa/PMJP, editada pelo autor com base nos dados de Lavieri e Lavieri (1992). governo federal na distribuição da população nos bairros da cidade já eram evidentes: a Avenida Epitácio Pessoa e adjacências já concentravam 32\% da população da cidade em 1979, enquanto áreas tradicionais como o Centro e Torre juntos abrigavam 15\% dos pessoense (LAVIERI e LAVIERI, 1992).

O perfil socioeconômico de diversos bairros também foi alterado, e antigos redutos da elite como Trincheiras e Tambiá passaram a ter a segunda menor renda média familiar de João Pessoa, igualando-se aos bairros originalmente populares, como Jaguaribe e Cruz das Armas (Figura 5).

\section{A Rua das Trincheiras entrincheirada}

Sendo o retorno financeiro, e não a redução do déficit habitacional, a principal preocupação do BNH e SFH, para autores como Cavalcanti (1999) esse tipo de atuação foi instrumental para que nas cidades brasileiras se criasse uma dinâmica de restrição no acesso às terras urbanas. Ao excluir a população que não conseguia inserir-se no mercado formal da habitação bem como os mutuários inadimplentes, a segregação socioespacial de João Pessoa era aprofundada e seus cidadãos marginalizados eram impelido a ocupar áreas desprezadas pelos promotores imobiliários e pelo poder 
Figura 6: Imagem aérea com a remoção integral da Saturnino de Brito. Fonte: Acervo pessoal de Rafael Targa, 2016 público, como manguezais, margens de ferrovias, bairros periféricos, deterioradas áreas centrais (Varadouro) e pericentrais (Roger, Cordão Encarnado) (CAVALCANTI, 1999).

O Cordão Encarnado é importante para compreender a apropriação da Rua das Trincheiras e de suas imediações após a ruptura do local com a elite que ali residiu. Foi neste local que surgiu a Favela Santa Emília de Rodat em 1962, uma das primeiras favelas de João Pessoa, e que nas décadas seguintes continuou a receber novos assentamentos, a exemplo da Favela Saturnino de Brito, situada às margens da Rua das Trincheiras (NASCIMENTO, 2012). Assentada em área de domínio municipal e localizada em Zona Especial de Preservação pelo Plano Diretor da cidade de 2012, o primeiro registro da Favela Saturnino de Brito data de 1978, apesar de seu reconhecimento pela prefeitura ter ocorrido apenas em 1981.

A favela continuou seu crescimento espacial no século XXI, e em 2012 sua área total aproximava-se dos 4,8 hectares e possuía 1291 habitantes distribuídos em 421 residências. Todavia, por ser considerada uma área com risco alto de deslizamento e uma das onze favelas mais vulneráveis da cidade em levantamento conduzido em 2006 pela Coordenadoria Municipal de Defesa Civil da Prefeitura Municipal de João Pessoa (COMDEC/PMJP), um projeto de intervenção urbanística foi elaborado pela própria PMJP, consistindo na relocação das residências para um local próximo e na construção de uma série de equipamentos como um centro comunitário, dois centros comerciais, praças, áreas de lazer, e uma ciclovia. Em março de 2016 a pesquisa de dissertação constatou que a execução do projeto já estava em andamento, sendo realizada a demolição integral dos domicílios e iniciada a construção dos edifícios residenciais no local predeterminado (Figura 6).

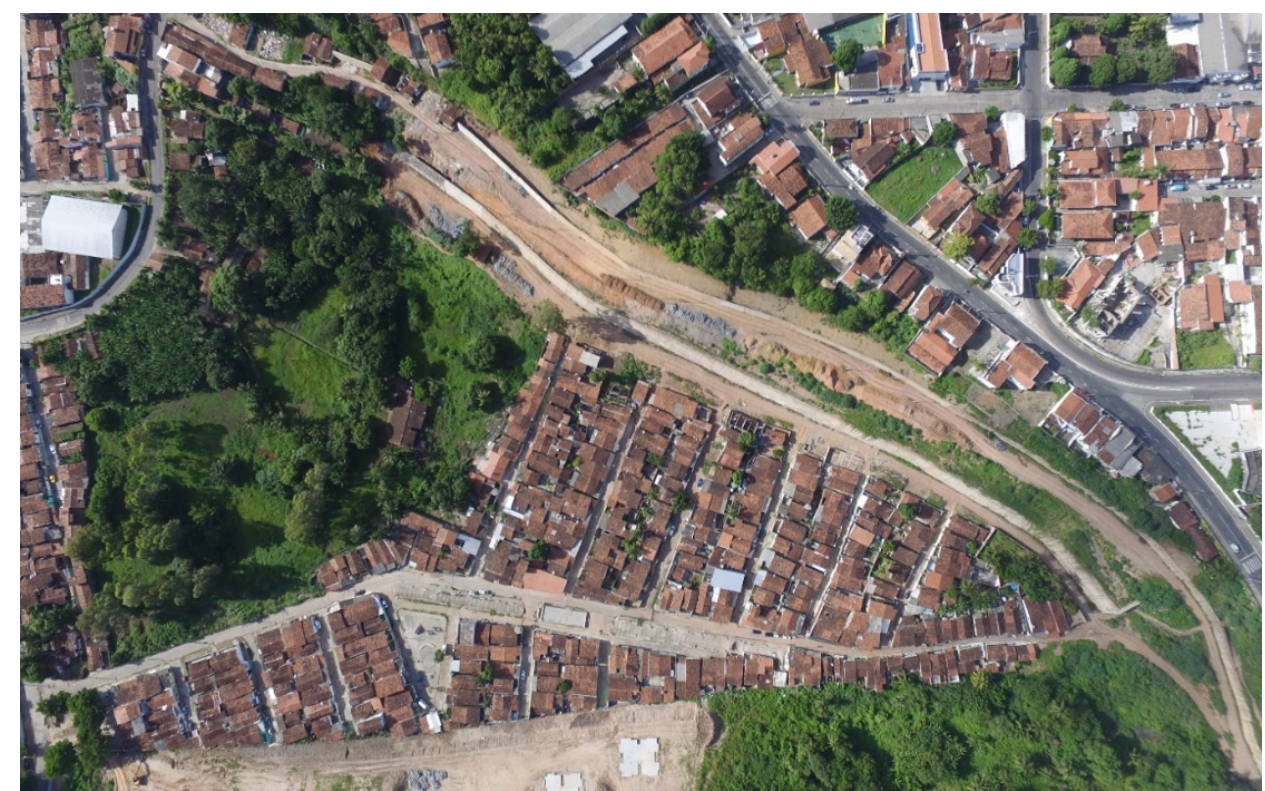


Figura 7: Localização das favelas nas imediações da Rua das Trincheiras e identificação de imóveis ocupados no local. Fonte: Planta Base da Cidade de João Pessoa/ PMJP, editada pelo autor, 2017.

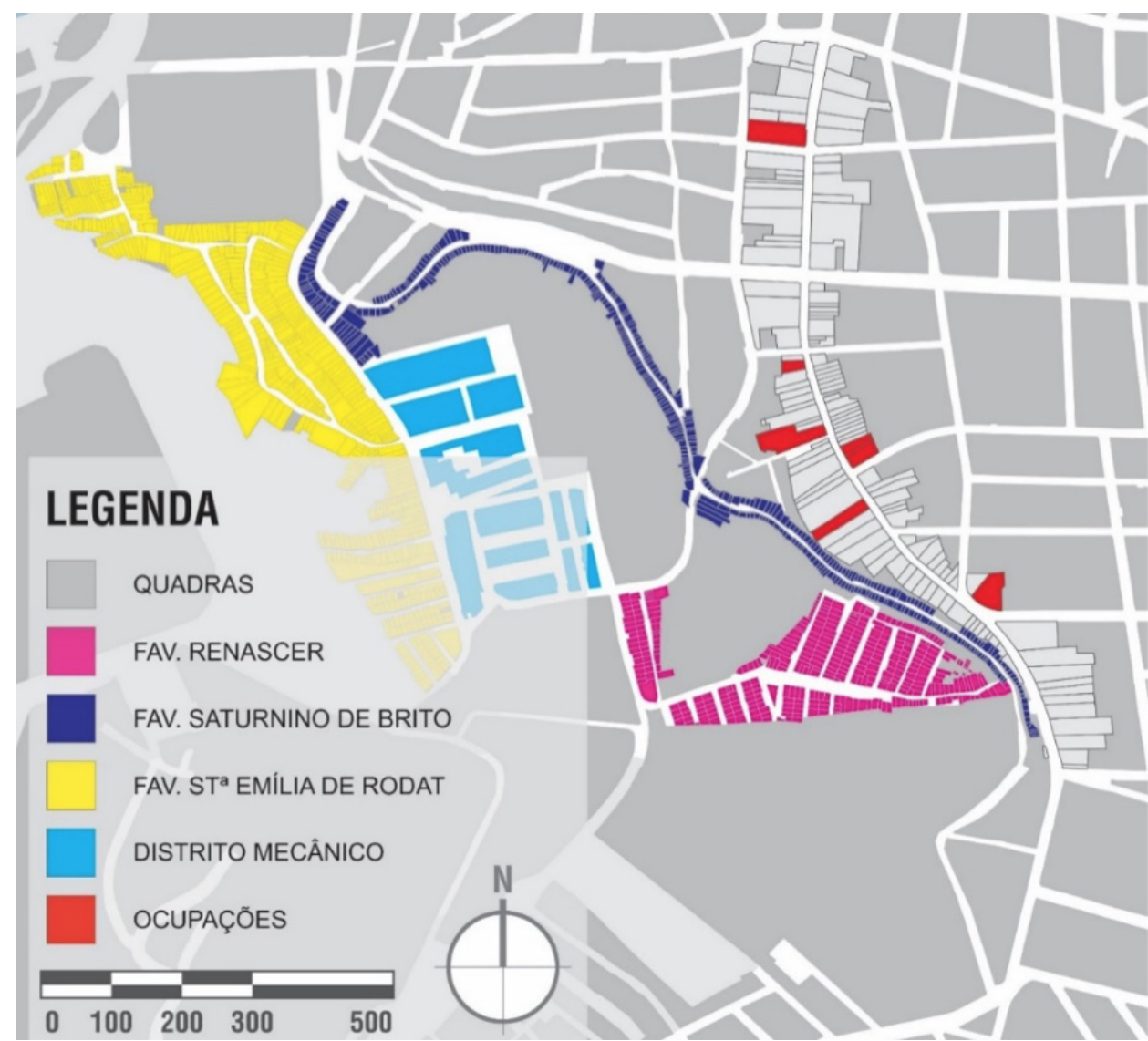

Mesmo com a relocação da favela iniciada na ocasião, as relações sociais que a mesma travou com a Rua das Trincheiras e seus casarios persistem, impactando a dinâmica urbana do local há mais de quarenta anos. Parte dessa relação foi esclarecida por um dos líderes do Movimento de Moradia, Ação e Luta Comunitária (MALC) que revelou que, além da apropriação da Rua Saturnino de Brito, dos fundos dos lotes da Rua das Trincheiras, e da balaustrada da Avenida João da Mata, quando ocorria deslizamento na encosta da favela, os moradores das residências atingidas recorriam à ocupação dos imóveis abandonados da rua para se abrigarem. Essa estratégia não acabou com o início da relocação da comunidade: diante da demolição das casas situadas no talude antes, sequer, do início da construção das novas residências, e do valor irrisório do auxílio-aluguel $(\mathrm{R} \$ 200,00)$, parte da população da Saturnino de Brito, composta em grande parte por ambulantes e catadores de lixo que realizam seus trabalhos na Área Central, ainda prefere ocupar os imóveis "abandonados" do que morar em locais periféricos (Figura 7).

Como resultado, o cerceamento por uma população de baixa renda, estigmatizada e marginalizada iniciado nas primeiras décadas do século XX e impulsionado na segunda metade do século XX pelo desenvolvimento de territórios "populares" em suas porções oeste (Favela Saturnino de Brito), leste (Jaguaribe) e sul (Cruz das Armas), avança para 
a Rua das Trincheiras e apodera-se de suas antigas mansões nos anos 2000. Novos conflitos de interesse surgem em decorrência desse processo, e o local persiste como um espaço de disputas entre proprietários fundiários, promotores imobiliários, Estado e grupos sociais excluídos.

\section{Considerações finais}

Os diagnósticos sobre o estado de conservação dos imóveis "em situação de risco" listados pelo IPHAEP após anos de atuação do órgão e a pesquisa empreendida no mestrado - no qual invalidou a hipótese inicial de que o processo de "abandono" e degradação dos imóveis no local era resultado da descentralização urbana de João Pessoa efetivada na década de 1980 - exprimem bem a peculiar dinâmica local.

No desenvolvimento da dissertação a análise da produção desse espaço urbano pautada na matriz marxista-lefebvriana foi instrumental para elucidar essa dinâmica da Rua das Trincheiras e compreender o local tanto em sua dimensão histórica quanto social. Ao considerar as relações dialéticas entre espaço/sociedade em importantes momentos de sua produção, o vínculo do local com as elites que nele fixaram moradia no início do século XX emergiu como determinante para, primeiramente, conferir prestígio do locus na malha urbana, fomentar a instalação de equipamentos modernos e colocar seus residentes e usuários no centro de importantes decisões políticas.

Essa elite letrada, uma vez que acumulava prestígio intelectual, econômico e político, pôde colaborar na imposição de novos conhecimentos e comportamentos na cidade, fazendo circular medidas voltadas ao ajustamento da população às novas regras de vida, costumes e trabalhos urbanos. (GUEDES, 2006, p. 20)

Parte da influência política de seus habitantes era vista na idealização e recomendação de políticas de regulação dos hábitos e expulsão da população mais pobre do centro citadino e suas implementações pelo Estado o que, por sua vez, promoveram a ocupação de áreas periféricas situadas à sul. Apesar da inicial distância resguardada dos sítios de Jaguaribe e Cruz das Almas ao bairro de Trincheiras, a inegável importância da população operária que ali residiam possibilitou que estes locais passassem a ser servidos pelo sistema de bonde. Com a instalação do equipamento, as espacialidades dos sítios de Cruz das Almas e Jaguaribe foram alteradas, sua urbanização acelerada e suas ocupações insufladas.

As repercussões do sistema não se restringiram à expansão dos limites dos bairros, também alterando as relações sociais entre seus habitantes e os vizinhos abastados. A aproximação da população mais pobre em sua vizinhança promoveu uma fissura no vínculo das elites com o bairro das Trincheiras e rua homônima. Entretanto, apenas quando um novo padrão de mobilidade urbana e de produção do espaço, pautados na articulação do sistema viário com a ocupação do solo através do loteamento de grandes vazios, foram inaugurados no território nacional e municipal, que a ruptura da elite com o local concretizou-se. Novos bairros nobres surgiam na malha urbana, principalmente no eixo leste (Centro-Praia), apoiado na Avenida Epitácio Pessoa. O mercado imobiliário e o Estado passaram a promover o consumo urbano através da ocupação desses novos territórios, apelando aos desejos da classe média e logrando êxito graças ao aumento da motorização dessa camada. 
Por sua vez, os empreendimentos no setor sul, conduzido pela Avenida Cruz das Armas - prolongamento da Rua das Trincheiras - buscavam disciplinar as ocupações espontâneas e combater a presença de mocambos que ainda marcavam a paisagem dos bairros. A partir de 1964 os perfis socioeconômicos dos empreendimentos e do públicoalvo são reforçados pela atuação do BNH e do SFH e, diante do aprofundamento da segregação socioespacial gerado, os habitantes das camadas mais altas deslocaram-se para os novos bairros "nobres" que surgiam e deixaram uma retaguarda abandonada na Área Central.

Assim, os novos padrões de mobilidade e produção, além da superação dos limites territoriais centenários, "[...] num rompimento definitivo do padrão de relativa convivência entre membros de distintas classes sociais herdado do período colonial [...] e na configuração de um 'processo mais radical de seletividade no espaço urbano da cidade' (Cavalcanti, 1999, apud TRAJANO FILHO, 2006, n.p).

A efetivação do distanciamento dos vizinhos estigmatizados é um exemplo deste rompimento no tecido social pessoense, uma vez que serviu como catalisador na apropriação de espaços como a Rua das Trincheiras e entorno por uma população de baixa renda. A ocupação de terras indesejadas, muitas de domínio municipal, e de edifícios "abandonados" para garantir o acesso a bens e serviços dessa população, por sua vez, promove um maior acirramento dos conflitos entre diferentes grupos envolvidos na produção, na apropriação e na gestão urbana da cidade pois acentua o desinteresse de herdeiros dos imóveis e de novos promotores imobiliários no local, agravando a desvalorização do solo. Todavia, é justamente essa ocupação que permite resiliência ao uso tradicional da rua - residencial - frente ao incessante surgimento de vazios urbanos no local e ao progressivo arruinamento de seus exemplares arquitetônicos.

\section{Referências bibliograficas}

AFONSO, F. V.; COSTA, S. B. V. D. As novas (e não tão novas) moradias para uma cidade em expansão: a Avenida Epitácio Pessoa. In: MOURA FILHA, M. B.; COTRIM, M.; FILHO (ORG.), I. C. Entre o rio e o mar: arquitetura residencial na cidade de João Pessoa. João Pessoa: Editora da UFPB, 2016. p. 232-255.

ARAÚJO, A. L. D. A residência dos bairros populares: morar em Jaguaribe. In: MOURA FILHA, M. B.; COTRIM, M.; FILHO (ORG.), I. C. Entre o rio e o mar: arquitetura residencial na cidade de João Pessoa. João Pessoa: Editora da UFPB, 2016. p. 256-277.

CAVALCANTI, J. B. A política habitacional do BNH no Brasil pós-64 e seus reflexos na expansão urbana de João Pessoa. João Pessoa: Universitária - UFPB, 1999.

CHAGAS, W. F. As singularidades da modernização na cidade da Parahyba nas décadas de 1910 a 1930. Recife: Tese de Doutorado. Programa de Pós-Graduação em História - UFPE, 2004.

CLEMENTE, J. C. Vazios urbanos e imóveis subutilizados em áreas centrais históricas Um estudo na cidade de João Pessoa. João Pessoa: Dissertação de Mestrado - Programa de Pós-Graduação em Engenharia Urbana e Ambiental, 2012

GUEDES, K. A. O Ouro Branco abre caminhos: o algodão e a modernização do espaço urbano da cidade da Parahyba (1850-1924). Natal: Dissertação de Mestrado. Programa de Pós-Graduação em Arquitetura e Urbanismo. UFRN, 2006.

LAVIERI, J. R.; LAVIERI, M. B. Evolução da Estrutura Urbana Recente de João Pessoa (1960 1986). Textos UFPB - NDHIR, $n^{\circ} 29$, Julho 1992. 
LEFEBVRE, H. La producción del espacio. 1ª. ed. Madri: Capitan Swing II, 2013.

MARTINS, P. D. Paisagem em movimento: As transformações na Avenida Presidente Epitácio Pessoa de 1980 a 2001. João Pessoa: Dissertação de Mestrado. Programa de Pós-graduação em Arquitetura e Urbanismo. UFPB, 2014.

MEDEIROS FILHO, J. E. O bonde à burro na historiografia da Cidade da Parahyba. In: PEIXOTO, E. R., et al. Tempos e escalas da cidade e do urbanismo. Anais do XIII Seminário de História da Cidade e do Urbanismo. Brasília, DF: Universidade Brasília- Faculdade de Arquitetura e Urbanismo, 2014. Disponivel em: <http://www.shcu2014.com.br/content/bonde-burro-na-historigrafia-da-cidade-da-parahyba>.

MOURA NETO, A. V. D. L. E.; MOURA FILHA, M. B.; PORDEUS, T. R. Patrimônio arquitetônico e urbanístico de João Pessoa - um pré-inventário. João Pessoa: Trabalho Final de Graduação (Arquitetura e Urbanismo). UFPB, 1985.

NASCIMENTO, A. C. A. V. D. A construção do informal: uma análise morfológica das favelas da cidade de João Pessoa. João Pessoa: Dissertação de Mestrado. Programa de Pós-graduação em Engenharia Urbana e Ambiental. UFPB, 2012.

SÁ, N. L. A. R. A cidade no despertar da era higiênica: a Cidade da Parahyba e o Movimento Higienista (1854 - 1912). João Pessoa: Dissertação de Mestrado. Programa de Pós-Graduação em Geografia. UFPB, 2009.

SANTOS, M. A urbanização brasileira. São Paulo: EdUSP, 1993.

TINEM, N. (. ). Fronteiras, marcos e sinais. Leituras das ruas de João Pessoa. João Pessoa: Editora UFPB, 2006.

VIDAL, W. C. L. Transformações Urbanas: a modernização da capital paraibana e o desenho da cidade, 1910 - 1940. João Pessoa: Dissertação de Mestrado. Programa de Pós-graduação em Engenharia Urbana e Ambiental. UFPB, 2004.

. Uma cidade em expansão: outros caminhos se definem. In: MOURA FILHA, M. B.; COTRIM, M.; FILHO (ORG.), I. C. Entre o rio e o mar: arquitetura residencial na cidade de João Pessoa. João Pessoa: Editora da UFPB, 2016. p. 156-175.

VILLAÇA, F. O espaço intra-urbano no Brasil. São Paulo: Studio Nobel, 1998. 